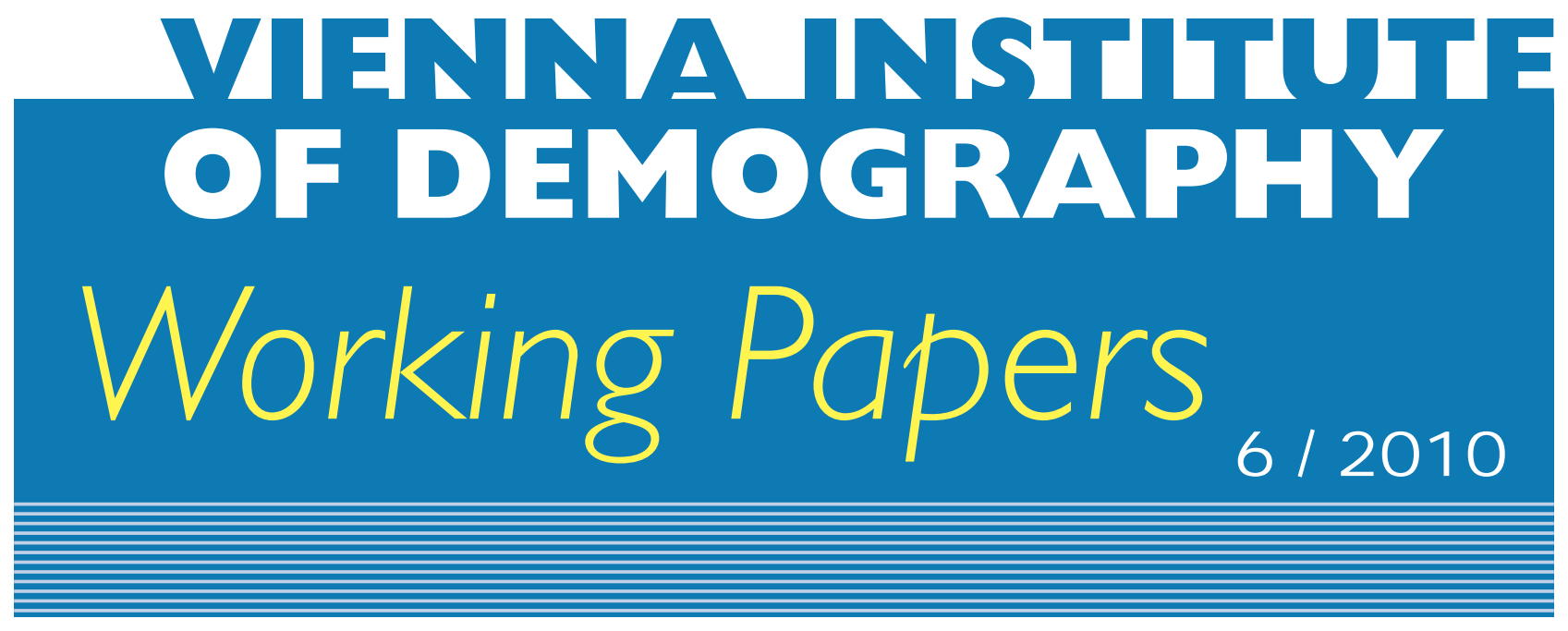

Bilal Barakat, Johannes Holler, Klaus Prettner, and Julia Schuster

\title{
The Impact of the Economic Crisis on Labour and Education in Europe
}

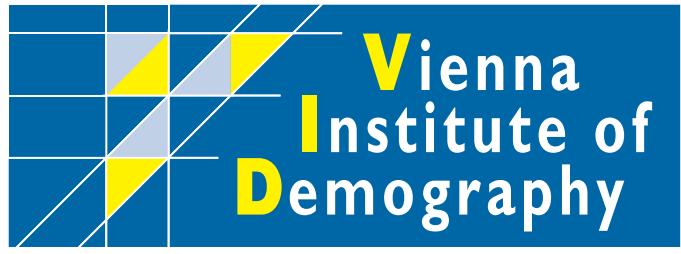

Vienna Institute of Demography Austrian Academy of Sciences

Wohllebengasse I2-14

A-I040Vienna $\cdot$ Austria

E-Mail:vid@oeaw.ac.at

Website: www.oeaw.ac.at/vid 


\begin{abstract}
In summer 2007, the US subprime crisis emerged and economic growth in industrialised countries started to slow down. The situation deteriorated after the default of Lehman Brothers in September 2008 and despite massive government interventions, the United States and most European countries slid into recession. We investigate the influence of the recent economic and financial crisis on European labour market perspectives and educational attainment decisions. Furthermore we disentangle the differential impacts of the crisis on various demographic subgroups. We find that young male workers have been hit hardest, while older workers and women have been partially protected by non-redeemable contracts and the fact that they work in sectors which have been less severely hit by the crisis. Focusing on the education sector, it seems that the demand for education increases because individuals try to circumvent the tight labour market, while the supply of education suffers because of the increased pressures on federal budgets in most European countries. However, we conclude that it is too early to make a definite statement because the full impact of the crisis on the education sector is still to come.
\end{abstract}

JEL classification: I20; J01; J10

\title{
Keywords
}

Economic crisis, labour market, education.

\section{Authors}

Bilal Barakat: Vienna Institute of Demography, Austrian Academy of Sciences, Wohllebengasse 12-14, A-1040, Vienna; email: bilal.barakat@,oeaw.ac.at.

Johannes Holler: Vienna Institute of Demography, Austrian Academy of Sciences, Wohllebengasse 12-14, A-1040, Vienna; email: johannes.holler@oeaw.ac.at.

Klaus Prettner: Vienna Institute of Demography, Austrian Academy of Sciences, Wohllebengasse 12-14, A-1040, Vienna; email: klaus.prettner@oeaw.ac.at.

Julia Schuster: Vienna Institute of Demography, Austrian Academy of Sciences, Wohllebengasse 12-14, A-1040, Vienna; email: julia.schuster@,oeaw.ac.at.

\section{Acknowledgements}

We thank Dimiter Philipov (Vienna Institute of Demography) for helpful comments and suggestions. This paper was prepared within the DemoNet project. 


\title{
The Impact of the Economic Crisis on Labour and Education in Europe
}

\author{
Bilal Barakat, Johannes Holler, Klaus Prettner, Julia Schuster
}

\section{Introduction}

Beginning with the US subprime crisis in summer 2007 and its negative effects on financial markets, economic growth in industrialised countries started to slow down. After the default of Lehman Brothers in September 2008 the situation deteriorated and despite massive government interventions, the US and most European countries slid into recession. Major labour market effects can be expected to result from such a development: Employment typically decreases and unemployment increases after a slowdown of GDP, albeit with a certain delay (Blanchard 2003).

Historically, European unemployment rates were low after the Second World War and amounted to merely 2 percent in the 1960s. However, these rates started to increase in the 1970s after the occurrence of the two oil price shocks and a general slowdown of productivity growth, which was not incorporated in the wage bargaining process between unions and firms. In the 1980s European unemployment increased further to around 8 percent because of the disinflationary policy of many Central Banks. Afterwards, during the late 1980s, the 1990s and the 2000s, European unemployment rates fluctuated cyclically around this high level (Blanchard 2006).

Before the current economic crisis hit Europe, the business cycle was in a stage where unemployment was generally decreasing (European Commission 2009). However, this trend stopped in 2008 and with a time lag of approximately one year, the recession translated into higher unemployment. This delay was partly caused by policy measures such as the adjustment of work hours taken to mitigate the negative employment effects. The increase in unemployment was not evenly shared between certain socioeconomic subgroups, and the biggest differences arose due to sex, age and educational attainment.

In the following, we look at the differential impact of the financial and economic crisis on the labour market as well as on the education sector. The remainder of this work is organised as follows: Section 2 disentangles changes in employment and unemployment between various demographic subgroups. Section 3 focuses on changes in demand for higher education as well as on crisis related impacts on educational funding and provision. Finally, section 4 draws conclusions and highlights the potential of certain policy instruments to cope with the negative impacts of the economic crisis. 


\section{Effects of the Economic Crisis on Labour Market Participation of Various Demographic Subgroups}

To provide a general overview, Figure 1 illustrates the steady decline in unemployment from the beginning of 2005 until the third quarter of 2008; the unemployment rate declined from around 9.5 percent down to 6.7 percent of the total labour force. However, during the subsequent 6 months unemployment increased again, reaching the level observed four years earlier.

\section{Figure 1}

Unemployment rates in the EU 27, by sex

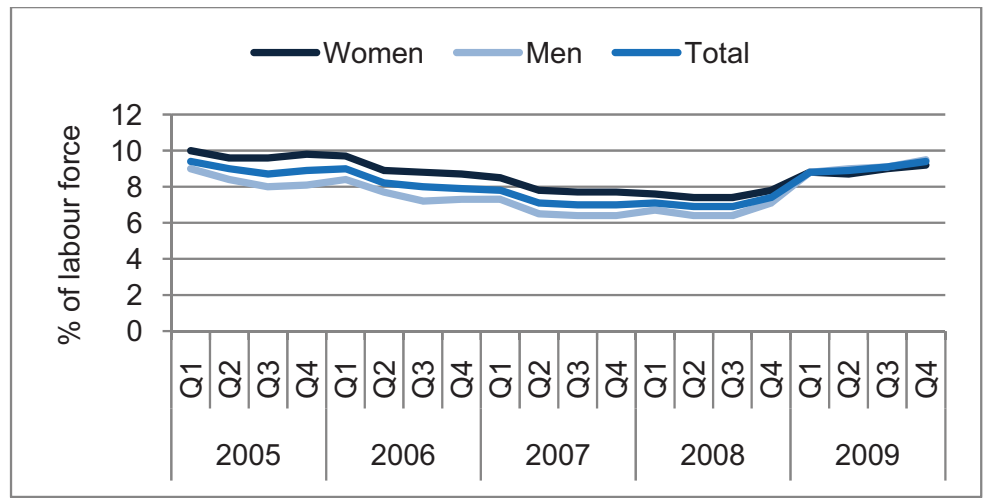

Source: Eurostat, Labour Force Survey

Regarding the projected evolution of the workforce, and therefore the projected future labour supply, Figure 2 shows that the working age population will start to shrink by 2014, while the amount of individuals aged 60+ will increase until 2025. This indicates that the supply side pressure on unemployment will increase till 2014 and should decrease from 2014 onwards. The demographic factors therefore will not favour a decline in unemployment during the next few years.

Figure 2

Population change over previous year, EU 27, 1995-2050

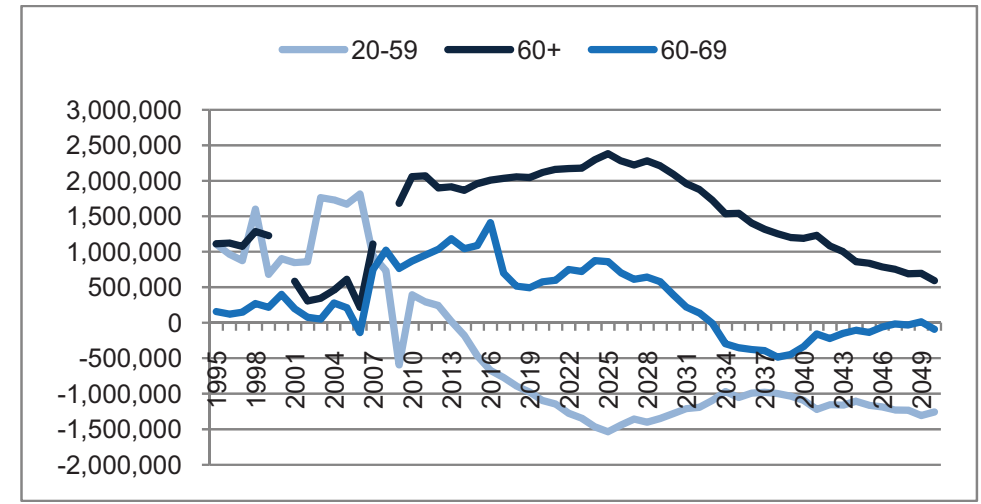

Source: Eurostat, EUROPOP2008 Convergence scenario 


\subsection{Unemployment by Sex}

Male unemployment rose from 6.5 percent in the third quarter of 2008 to 9.5 percent of the total labour force by the end of 2009 , while female unemployment rose from 7.4 percent to 9.2 percent of the total labour force. Figure 1 further highlights that the historically observed gap between female and male unemployment began to decrease in the beginning of 2008 and had closed by the first quarter of 2009. One reason for the strongly over-proportional increase in male unemployment can be identified by looking at the influence of the recession on certain economic sectors. Males have been more strongly by the cyclical unemployment because the economic downturn was mainly concentrated in the manufacturing and production sector. These male-dominated sectors were immediately affected by the economic crisis, while the main contraction of the female-dominated services sector occurred with a delay. An additional explanation for the smaller change in female unemployment can be found in the structure of work contracts: women are to a greater extent employed in part-time jobs which were less affected by the economic crisis (EC 2009) ${ }^{1}$.

Overall it can be expected, that the difference between levels of female and male unemployment will re-emerge in the future because (a) of the described time-lag between male- and female dominated and (b) that male-dominated sectors will also react faster to a recovery.

\subsection{Unemployment by Age}

The data further reveals that the unemployment increase affected certain age groups differently (see Figure 3). Youth unemployment (age 15-24) and prime working age unemployment (age 25-54) increased substantially, by 5.4 and 2 percentage points respectively, while old-age unemployment (age 55-64) rose only moderately by 1.2 percentage points. The observed variations can partly be attributed to existing differences in work contracts. Old employees are mainly holding indefinite contracts and benefit more from labour market protection. Furthermore, individuals who lose their jobs at older ages have the opportunity to retire instead of registering as unemployed. Therefore old-age unemployment is less affected than young unemployment. In general, if labour markets are very rigid, lower demand for labour mainly affects the inflows to the labour market which implies that the younger workforce is hit hardest.

\footnotetext{
${ }^{1}$ A recently published report by the European Commission (EC 2010) identifies the concentration of male labour in certain sectors as the main driver behind the differences in unemployment for men and women.
} 


\section{Figure 3}

Unemployment rates in the EU 27, by age groups

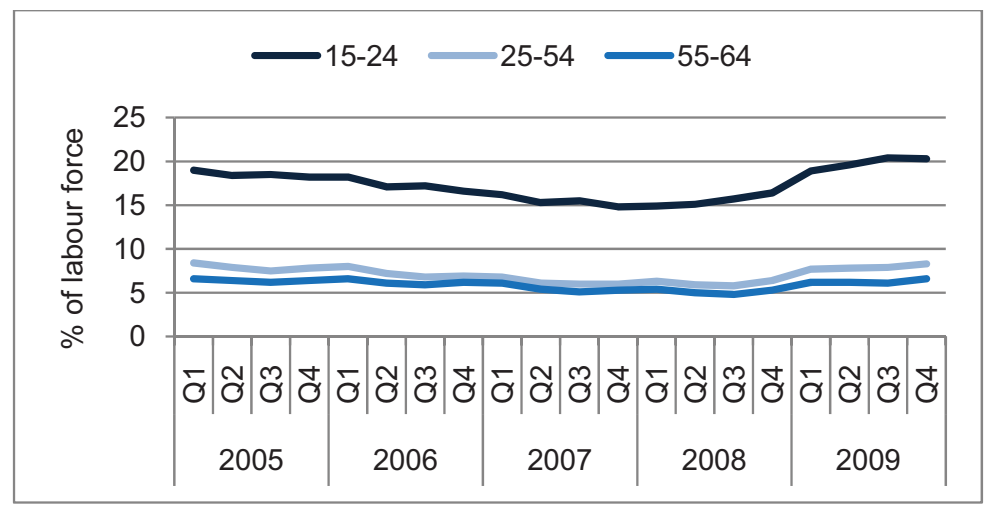

Source: Eurostat, Labour Force Survey

\subsection{Unemployment by Educational Attainment}

During the economic downturn educational attainment had a strong influence on job security. The unemployment rates of low-skilled workers increased by 3.9 percentage points, while the unemployment rate of medium-skilled and high-skilled workers only increased by 1.9 and 1.7 percentage points respectively (see Figure 4). This variation can again be attributed to the strength with which different economic sectors were hit by the economic crisis. The manufacturing and production sector, which mainly employs low and medium-skilled workers, was hit strongest, leading to a higher increase of unemployment for the corresponding skill groups. The variation of unemployment for certain skill levels highlights that the grade of substitutability for labour decides about the reaction of unemployment to an economic downturn. Easily substitutable labour will be affected most strongly.

Figure 4

Unemployment rates in the EU 27, by educational attainment

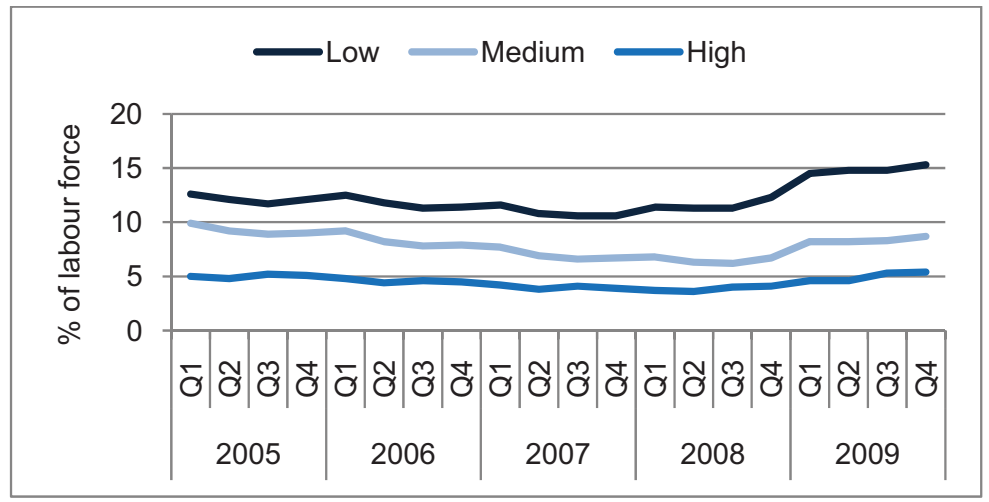

Source: Eurostat, Labour Force Survey 


\subsection{Employment among the Elderly}

According to the Lisbon strategy employment among people aged 55-64 should be above 50 percent of the corresponding labour force towards the year 2010. Figure 5 illustrates these levels for the $27 \mathrm{EU}$ member-states in 2009. Employment for both sexes of this age group is around 46 percent of the corresponding labour force for the whole EU, where only 12 member-states exceed the target of 50 percent. Evidently, the effect of the crisis will make it even harder to meet the Lisbon target.

Figure 5

Employment rates of older workers aged 55-64 in 2009, by sex in EU 27, in \%

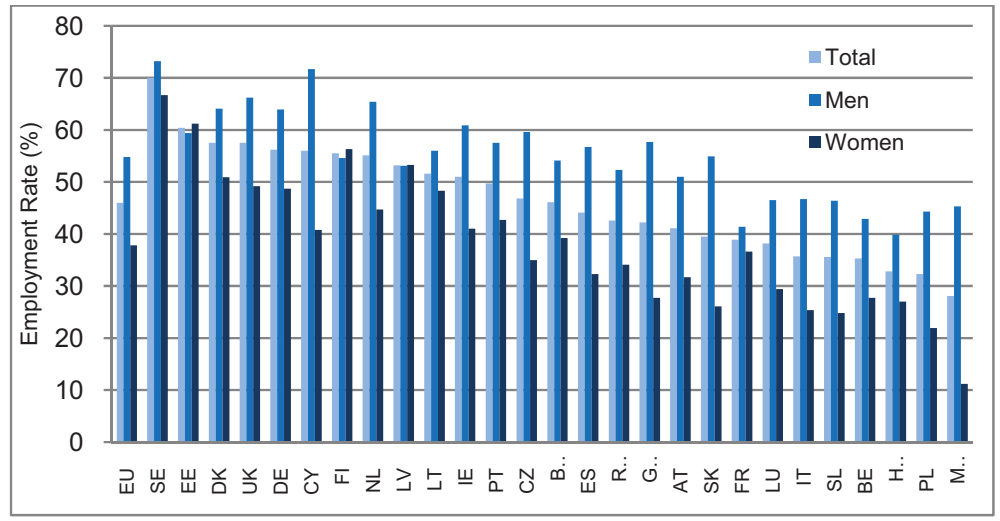

Source: Eurostat, Labour Force Survey

\section{Effects of the Economic Crisis on the Education Sector}

The effects of the crisis on the education sector are more difficult to assess for several reasons. Firstly, because of the rigid temporal structure of education systems, the effects themselves are slower to unfold, and secondly because statistical indicators for the education sector are generally only monitored annually and published with delay. Individual educational choices in response to the economic crisis (new or continued enrolment, for example) will in many cases have concerned the academic year 2009-10 at the earliest. Evidently we will only be able to assess these effects fully one or two years from now. On the supply side, much educational spending is non-discretionary, and changes to funding formulas, mandated staffing ratios or teacher salaries may require legislative action, with the associated delays.

The principal source for comparative education statistics is the data collection exercise performed jointly by Eurostat, OECD and the UNESCO Institute for Statistics (UIS), normally on an annual basis. At the time of writing the latest available year for routinely published data is for the years 2007-08; too early for the impact of the economic crisis to be observable. In recognition of the gap between available data and the information needs of educational policy-makers and agencies in the face of the crisis, a number of ad-hoc surveys have been conducted by the OECD, Education International (EI) and others. Accordingly, for a preliminary assessment of likely impacts of the crisis on 
education we are forced to rely on such surveys, the literature on the educational effects of past crises, and informed conjecture.

\subsection{Demand for Higher Education}

In the European context, demand arguments generally only apply to post-compulsory, and especially tertiary education. A number of a priori arguments suggest themselves. The crisis may act on enrolment in higher education in different and possibly contradictory ways, through direct and indirect channels.

On the one hand, students relying on financial support from their parents may face a shortfall if their parents' income drops due to unemployment or sinking equity in their property. Access to student loans may become more difficult in the context of restrictive lending policies. In addition to factors that negatively impact the affordability of study, the expected returns to a tertiary degree may also be perceived to have declined in the face of future job uncertainty.

On the other hand, young people may face an increased incentive to enrol in higher education as an alternative to unemployment, seeking either to actually increase their qualifications and thereby their employability, or to 'wait out' the crisis. Despite plausible demand-reducing effects, past experience suggests that "demand for higher education generally goes up during economic downturns" (Douglass 2010).

The current crisis appears to conform to this pattern. Empirical evidence, at least to the extent to which it shaped expert responses to OECD's survey, suggests that on the whole demand for higher education has increased. For nearly half the countries included in the response, demand was seen to have increased, with the remainder estimating the effect to be either neutral or unknown. No respondent estimated demand for higher education to have certainly decreased. Similarly to Norway and Sweden, in the UK, applications to universities for the academic year 2010-11 are reported by the central Universities \& Colleges Admissions Service (UCAS 2010) to have increased by over twenty percent over the previous year. This leap is large even against a trend of rising application figures that began prior to the crisis, and is interpreted by UCAS officials to reflect the economic situation.

This interpretation is reinforced by the observation that much of the increase is attributable to applicants above the age of 25 , whose share grew by over sixty percent in one year (UCAS 2010). Similarly, in Ireland applications by "mature" students increased by over thirty percent between 2008 and 2009 (OECD 2010).

This demand increase is a rational reaction to unemployment patterns by education (c.f. section 2). Even if these figures are not necessarily indicative of the labour market situation for youth specifically, it is evident that such statistics may play a part in youths' decision to enter or remain in education. 
An overall increase in demand for and enrolment in higher education in response to the crisis does not, however, imply that there are not cases, possibly numerous, in which individuals had to interrupt, postpone or abandon their plans for higher education enrolment due to economic hardship caused by the crises, either to themselves or their families. If increasing enrolment were mostly the result of students delaying graduation, rather than an increase in participation, this should not count as a positive effect. The different components of enrolment increases (increased entry, reduced drop-out, prolonged stay) need to be monitored separately.

\subsection{Educational Funding and Provision}

At a time of eroding tax bases and enormous public deficits, it is not surprising that in many instances public educational investments have been suspended, such as the construction of sports fields and purchase of laptop computers in Poland (EI 2009a), or seen severe cuts, as in Hungary or Latvia for instance (EI 2009b), the latter having seen teacher salaries being reduced by twenty percent in 2009, despite the fact that a teacher shortage has been diagnosed (Eurydice 2010). At the same time, "one can say that in much of the world, and in particularly among developed economies and the BRIC's (Brazil, Russia, India, and China), public investment in higher education has become a semi-protected part of national and regional budgets in the midst of the worst economic recession in more than six decades" (Douglass 2010, p. 24). Indeed, in many countries, in Europe as elsewhere, "education is an integral part of recovery plans" (Bray and Varghese 2009 , p. 2), and these countries have demonstrated a commitment to increasing funding for education. For example, in Ireland, the Department of Education and Science received and increased budget allocation for 2009 compared to 2008; one of only two government departments to do so, and several European countries have allocated large sums to the construction, refurbishment or maintenance of school buildings.

However, education spending contained in stimulus packages is not necessarily additional spending, since it might simply compensate for a shortfall in regular funding. This is true to a considerable extent in the U.S. (DPCE 2009), where at least $\$ 30$ billion of education funds in the federal American Recovery and Reinvestment Act will compensate for gaps in states' education budgets.

In the medium and long term, recovery spending may in fact have negative impacts on the education system. Where it is merely "pulled forward", it may come at the expense of education budgets in subsequent years. At the same time, its one-off nature means that it cannot be used for sustainable reform. This effect is exacerbated by the fact that it has in many cases been rushed, forcing investments to occur within existing frameworks. It is important with respect to educational investments that form part of stimulus packages, that "the primary focus of these initiatives is economic, rather than educational" (Blyth 2009, p. 1). As result we should be very cautious about expecting a positive impact on educational objectives.

The effects of the crisis on marketisation in education are ambiguous. Private investment in education is likely to have stagnated, based on anecdotal evidence and past 
experience during the Asian financial crisis (Thomas et al. 2004). At the same time, considerations of efficiency have been further emphasised on the public education agenda, moderated to some extent by the fact that the savings achieved are sometimes immediately reinvested. An example of this is provided by the Netherlands, where it is proposed to end student grants, but the saving of about $€ 1$ billion would remain in higher education (Douglass 2010, p. 15). The efficiency discourse concerns not only issues of pedagogy and institutional governance, but also the infrastructure investments. Indeed fears have been raised that the spending rush associated with stimulus packages may come at the expense of lower quality in school construction, as planning processes are expedited.

In the context of educational spending, it is crucial to distinguish between the governmental, local and institutional levels. Where, schools are funded by municipalities, changes in funding can vary greatly from locality to locality and, it is possible for there to be increased national investment, yet spending cuts at school level. Universities' autonomous budgets are also under pressure. In countries where higher education institutions are financially autonomous, university endowments invested in the stock market are known to have suffered substantial losses.

One segment of the education sector that may be expected to be tied particularly closely to the state of the economy is Technical and Vocational Education and Training (TVET), especially where employers play a major direct role, such as in Germany. As such, changing patterns of educational investment by private enterprises are important to take into account. A priori, one might expect "apprenticeship offers [to be] declining because of bankruptcy and a decline in business activity" (Hugonnier 2009, p. 12). The impact of the crisis on TVET appears to be mixed. According to OECD (2010) reports, the sector appears to have been negatively affected in Ireland, the Netherlands, Belgium, and Hungary. By contrast, in Germany, a significant shortage of training places as a result of the crisis could not (yet) be observed. This is reflected both in official statistics of youth seeking and obtaining apprenticeships and in survey responses among private enterprises.

\section{Theoretical and Historical Perspectives}

\subsection{Historical vs. Current Economic Crisis}

The economic crisis of the 1970s, which was caused by a cut in oil production by the OAPEC (Arab states of the OPEC) that resulted in a huge increase of the oil price exhibits parallels as well as substantial differences concerning the labour market effects of the current economic slowdown (see Figure 6). Contrary to today's economic crisis, in 1974 when the curb in production started to translate into higher unemployment, female unemployment reacted more strongly than male unemployment. This reaction created the spread between male and female unemployment which was persistent until 2008. The increase in female labour participation that took place in the 1970s can be identified as the main driver of this evolvement. It appears that the economic crisis intensified the pressure on women to contribute to the family income. The data further highlights that while the economic crises of 1973 and 2007 affected the spread between female and male labour force, the crises of 1990 and 2001 did not substantially influence the relationship. The 
observed difference appears to be caused by the different extent to which the manufacturing and production sector was hit (e.g. the burst of the New Economy bubble in 2001 mainly affected the tertiary sector).

Figure 6

Unemployment rates in the EU15, by gender

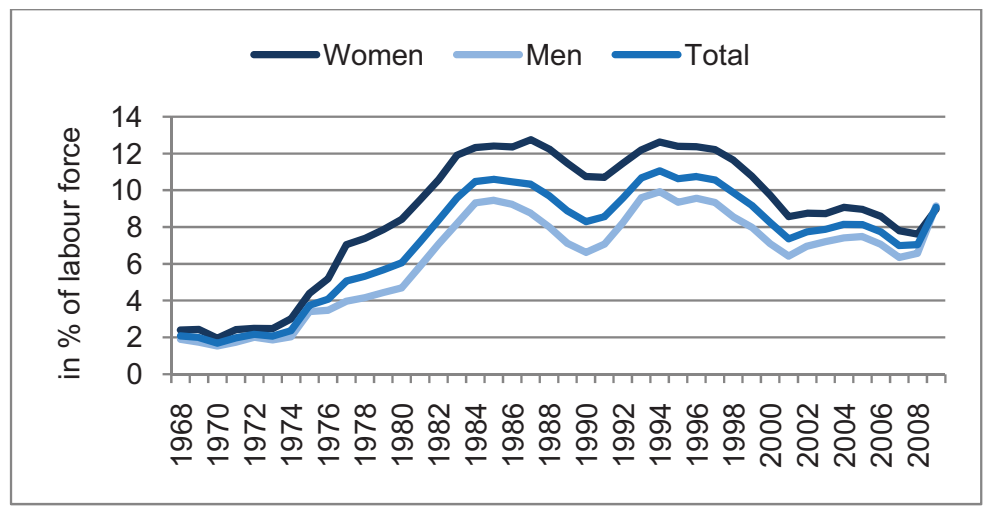

Source: Eurostat, Labour Force Survey

Focusing on age specific labour market impacts Figure 7 indicates that for all observed economic crises since the 1960s young workers were hit hardest. Nevertheless, due to their severity, the oil price crisis and the current economic crisis show a particular strong effect on youth unemployment. The overall evolution of unemployment for certain age groups highlights that the relevance of the spread between young and old workers is determined by the level of unemployment. To put it differently, in times when unemployment is very high, young workers are affected disproportionately, whereas in times when unemployment is very low and a shortage of labour exists, the gap between the youth and old-age unemployment is less pronounced.

Figure 7

Unemployment rates in the EU15, by age groups

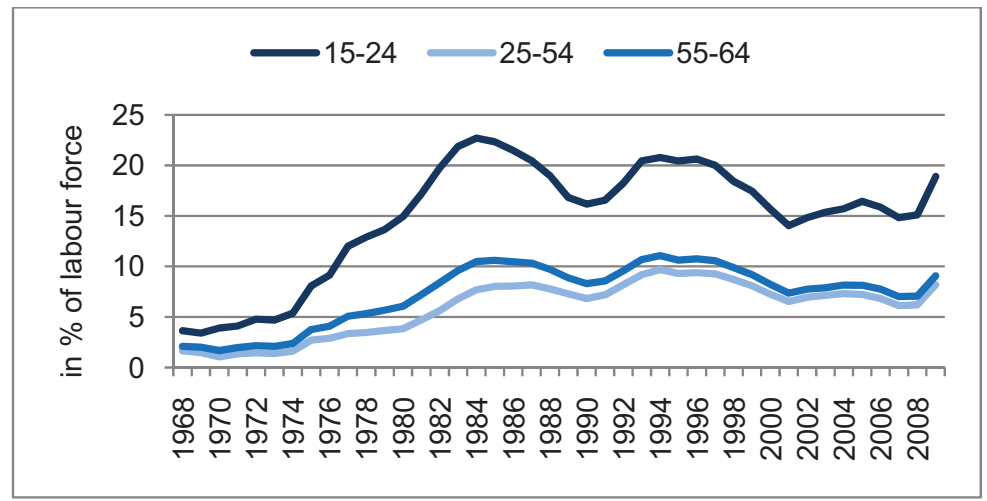

Source: Eurostat, Labour Force Survey 


\subsection{The Impact of the Economic Crisis in the Light of the Easterlin Hypothesis}

In the previous subsections we showed that the impacts of economic downturns on the labour market differed for certain demographic sub-groups and highlighted the role of labour market structure and composition in determining the strength of labour market reactions. Following arguments by Duesenberry (1949) and Easterlin (1987) we now briefly discuss these findings in light of theoretical arguments on the importance of the relative cohort size.

It is obvious that in a tight labour market environment where labour is scarce, economic crises increase unemployment less than in times where labour is abundant. Increasing relative cohort size, a crucial element of labour supply, therefore additionally spurs unemployment while the converse holds true for decreasing relative cohort size. Following this argument, part of the strong increase in youth unemployment that followed the oil price crisis in 1973 has to be attributed to the entry of the post world war baby boom generation into the labour market. Talking about today's crisis, the pressure on the labour market can be expected to be reduced by the contraction in labour force that occurs from year 2014 onwards.

\section{Conclusions and Policy Implications}

In this paper we aimed at identifying the different impacts of the economic crisis on the labour market perspectives of various demographic subgroups. Furthermore and closely related, we assessed the effects of the economic downturn on individual's desire for as well as on public funding of education. We have seen that young workers, especially those who are not highly educated, have to carry most of the burden of the economic slowdown. Moreover we have shown that the unemployment gap between women and men has narrowed but we expect this to be a transient effect. While the recession clearly led to cyclical unemployment, the long-run effect on structural unemployment is ambiguous. On the one hand, there is the danger that cyclical unemployment becomes persistent structural unemployment. On the other hand, the intensified pressure on the labour markets reduces rigidities and eases the labour matching process, which has the potential to curb long-run

unemployment. The education sector in Europe has not, to this point, suffered the threat of serious damage as a direct consequence of the crisis, as it has in many developing countries. This has to remain a preliminary conclusion, however, since some of the potentially harmful effects may lag by several years.

From a historical perspective we have seen that earlier economic crises affected the gap between youth and old-age unemployment as well as the gap between male and female unemployment differently. While the gap between female and male unemployment widened in the aftermath of the oil price crises which can be attributed to the additional inflow of female workers into the labour force, the gap decreased considerably in the current economic crisis which is due to the differential impact of the crisis on female and male-dominated sectors. In case of the age-specific gap in unemployment this work shows that economic crises had a pronounced negative impact on youth unemployment when the 
general level of unemployment was already high. The reason is that due to the rigidities in the contracts for older workers, youth unemployment is much more volatile than old-age unemployment and therefore its adjustments to labour shortages and labour abundances is much more pronounced.

Next to the immediate responses of labour markets due to the economic downturn, the economic crises led to certain policy measures that have been influencing labour markets in the past. The financial market turmoil led to a severe contraction of confidence in the risk measurement ability of markets. As an immediate response markets also re-evaluated risk connected to governmental insolvency, putting public debt at the centre of public perception. As a consequence, contractionary fiscal policy became a main point on the political agenda throughout Europe. In the short-run, the resulting lower government spending and higher taxation has the potential to further increase unemployment. Besides this change in fiscal policy, the public debt crisis, which resulted in the bailout for Greece, led to a loosening of monetary policy by the European Central Bank. In the short-run expansionary monetary policy is likely to decrease interest rates and therefore increases output and decreases unemployment. As a side-effect, this policy comprises inflationary risk. Potentially higher inflation would result in the evaporation of the positive employment effect in the medium-run.

Aside from monetary and fiscal policies, which are able to influence changes in unemployment in the short run, the focus of policy measures has to lie on educational investments. First, this is implied by the fact that better educated workers are less likely to suffer from unemployment in general. Second, human capital accumulation as a main driving force behind economic growth (see for example Lucas 1988) can compensate for the shrinking future labour force projected for Western Economies and especially Europe. Altogether the decomposition of labour market effects of the economic crisis for certain demographic sub-groups suggests that policy measures should especially focus on young and uneducated individuals. 


\section{References}

Blanchard, O. J. (2003): Macroeconomics. Prentice Hall. Upper Saddle River, NJ, 2003.

Blanchard, O. J. (2006): European unemployment: the evolution of facts and ideas. Economic Policy, Vol. 21, No. 45, p. 5 - 59.

Blyth, A. (2009). School buildings in today's crisis. CELE Exchange, Centre for Effective Learning Environments.

Bray, M. and Varghese, N. V. (2009). Education and the economic crisis. In IIEP Newsletter, volume XXVII. UNESCO International Institute for Educational Planning (IIEP), Paris.

Duesenberry, J. S. (1949): Income, Saving and the Theory of Consumer Behaviour. Cambridge, MA: Harvard University Press.

Douglass, J. A. (2010). Higher education budgets and the global recession: Tracking varied national responses and their consequences. Research \& Occasional Paper 4.10, Center for Studies in Higher Education (CSHE), University of California, Berkeley.

DPCE (2009). Educational Impact of the American Recovery and Reinvestment Act. Domestic Policy Council Executive Office of the President / U.S. Department of Education.

Easterlin, R. A. (1987): Birth and Fortune, 2nd edn. Chicago: University of Chicago Press.

EI (2009). The Global Economic Crisis and Its Impact on Education. Brussels: Education International (EI).

EI (2009a). Education: The Cost of the Crisis. A study on the effects of loans from international financial institutions on the education sector in Central and Eastern Europe and Central Asia. Brussels: Education International (EI).

EI (2009b). Brief overview: the impact of the financial and economic crisis on education in CEE countries: A summary of answers received to four key questions sent to EI affiliates attending the High Level Seminar \& initial responses to the follow-up survey on the impact of the crisis on education. Brussels: Education International (EI).

European Commission (2009): Employment in Europe 2009.

URL:http://ec.europa.eu/social/main.jsp?catId=119\&langId=en [Accessed: 02/07/2010]

European Commission (2010): EU labour market behaviour during the Great Recession. URL:

http://ec.europa.eu/economy finance/publications/economic paper/2010/pdf/ecp405 en.p df [Accessed: 02/07/2010] 
Eurydice (2010). Eurybase Database. URL:

http://eacea.ec.europa.eu/education/eurydice/eurybase en.php [Accessed 22/06/10]

Hugonnier, B. (2009). Innovative investments in education in OECD countries. In IIEP Newsletter, volume XXVII. UNESCO International Institute for Educational Planning (IIEP), Paris.

ILO (2009). Impact of the global economic recession on education. Sector note, International Labour Organization (ILO).

Lucas, R. E. (1988): On the mechanics of economic development. Journal of Monetary Economics Vol. 22, pp. $3-42$.

Morduchowicz, A. (2009). Latin America and the crisis. In IIEP Newsletter, volume XXVII. UNESCO International Institute for Educational Planning (IIEP), Paris.

OECD (2010). Summary of the initial education today crisis survey: Impact of the economic crisis on education. EDU Working Paper 43, OECD.

Prakash, B. (2009). Towards a framework for examining the global economic and financial crisis and its impact on education. Mimeo, UNESCO, Paris.

Thomas, D., K. Beegle, E. Frankenberg, B. Sikoki, J. Strauss, G. Teruel (2004). Education in a Crisis. Journal of Development Economics, 74, 53-85.

UCAS (2010). Online statistical database. University \& College Admissions Service. URL: http://www.ucas.ac.uk/about_us/stat_services/ [Accessed: 02/07/2010]

UNESCO (2009). Concept paper on the impact of the economic and financial crisis on education. Prepared for the tenth meeting of the working group on education for all (EFA), 9-11 December 2009, UNESCO, Paris. 


\section{VIENNA INSTITUTE OF DEMOGRAPHY}

\section{Working Papers}

Grafeneder-Weissteiner, Theresa and Klaus Prettner, Agglomeration Processes in Ageing Societies, VID Working Paper 05/2010.

Buber, Isabella, Parity-specific weights for the Austrian Generations and Gender Survey, VID Working Paper 04/2010.

Testa, Maria Rita, She wants, he wants: Couple's childbearing desires in Austria, VID Working Paper 03/2010.

Buber, Isabella, Wissenschaftlerinnen in Österreich - Zusatzerhebung im Rahmen des GGS.Dokumentation der Datenerhebung und deskriptive Ergebnisse, VID Working Paper 02/2010.

Kuhn, Michael, Stefan Wrzaczek, Alexia Prskawetz, and Gustav Feichtinger, Externalities in a Life-Cycle Model with Endogenous Survival, VID Working Paper 01/2010.

Prettner, Klaus, Population Ageing and Endogenous Economic Growth, VID Working Paper 08/2009.

Št’astná, Anna and Tomáš Sobotka, Changing Parental Leave and Shifts in Second and Third-Birth Rates in Austria, VID Working Paper 07/2009.

Prettner, Klaus and Alexia Prskawetz, Decreasing Fertility, Economic Growth and the Intergenerational Wage Gap, VID Working Paper 06/2009.

Wegner, Christian and Marc Luy, Determinants of General Health and Specific Diseases of Elderly Women and Men: A Longitudinal Analysis for Western and Eastern Germany, VID Working Paper 05/2009.

Wrzaczek, Stefan, Michael Kuhn, Alexia Prskawetz, and Gustav Feichtinger, The Reproductive Value in Distributed Optimal Control Models, VID Working Paper 04/2009.

Wendland, Maike und Isabella Buber, Ein Vergleich der Ergebnisse der ersten Welle des Österreichischen,, Survey of Health, Ageing and Retirement in Europe " (SHARE) und der „Österreichischen Gesundheitsbefragung“ (ATHIS), VID Working Paper 03/2009.

The Vienna Institute of Demography Working Paper Series receives only limited review. Views or opinions expressed herein are entirely those of the authors. 